\title{
Riche-Cannieu connection in median nerve injuries
}

\author{
MM Carr DDS MD, JB Boyd MD FRCS FRCSC FACS, CVA Bowen MD FRCSC \\ $\mathrm{MBChB}$ \\ Department of Surgery, University of Toronto and Divisions of Orthopaedic and Plastic \\ Surgery, Toronto Hospital, General Division, Toronto, Ontario
}

\begin{abstract}
MM Carr, JB Boyd, CVA Bowen. Riche-Cannieu connection in median nerve injuries. Can J Plast Surg 1996;4(2):117-120. The Riche-Cannieu connection between the deep branch of the ulnar nerve and the recurrent motor branch of the median nerve was first noted in hand dissections almost 100 years ago. It was then considered rare and unimportant. Electrophysiologists have recently shown that this connection occurs in a large proportion of normal volunteers and accounts for a variable proportion of motor response in the thenar musculature. This report describes two cases of median nerve injuries with intact thenar function and postulates that this anomalous clinical presentation is due to the Riche-Cannieu connection. The unusual clinical situations emphasize the need for careful evaluation of nerve injuries.
\end{abstract}

Key Words: Hand surgery, Peripheral nerve anomalies, Peripheral nerves injuries

\section{Connexion de Riche-Cannieu dans des lésions nerveuses médianes}

RÉSUMÉ : La connexion de Riche-Cannieu entre la branche profonde du nerf cubital et la branche récurrente motrice du nerf médian a tout d'abord été notée lors de dissections de la main il y a près de 100 ans. On considérait alors ce phénomène rare et peu important. Les électrophysiologistes ont récemment démontré que cette connexion survient chez une importante proportion de volontaires normaux et pourrait expliquer la proportion variable de réponse motrice au niveau de la musculature thénar. Ce rapport décrit deux cas de lésion du nerf médian, laissant la fonction thénar intacte et postule que cette présentation clinique anormale soit attribuable à la connexion de Riche-Cannieu. Ces situations cliniques inhabituelles soulignent la nécessité d'évaluer attentivement les lésions nerveuses.

Trauma victims have long provided physicians with This case study discusses two patients with nerve injuries who presented with unusual clinical findings.

\section{CASE PRESENTATIONS}

\section{Case 1}

A 35-year-old, right hand dominant supermarket worker sustained a $2.5 \mathrm{~cm}$ laceration proximal to the right volar wrist crease on October 21, 1990 when a glass bottle exploded. He bandaged his injuries and continued with his work. That evening he 
noticed an area of numbness in his hand and presented at his local emergency room on the following morning. He was anesthetic in the radial three-and-a-half digits and had evidence of a motor deficit suggestive of a median nerve transection. Exploratory surgery was performed.

Under general anesthesia and tourniquet control the surgeon noted that the palmaris longus tendon and the median nerve were cleanly transected $1.5 \mathrm{~cm}$ proximal to the wrist. An epineurial nerve repair with good anatomical alignment and suture of the palmaris longus was undertaken. The wrist was immobilized with a dorsal plaster slab and the patient was discharged without incident.

Ten months later the numbness was unchanged and he had a positive Tinel's sign over the scar at the wrist. Thenar muscle bulk and strength were comparable with the opposite hand. Nerve conduction studies showed absent sensory response from the median nerve and marked prolongation of the motor latency. Electromyogram (EMG) of the abductor pollicis brevis (APB) showed increased polyphasic forms, some units of increased duration, and amplitude and occasional fibrillations.

One year after his injury the patient was referred to the senior author because his sensory deficit had not improved. The patient reported episodes of cutting his right index finger without realizing the incident had taken place. On examination he had no light touch or pain sensation in the median nerve distribution. His right ulnar nerve was blocked at the wrist with local anesthetic, resulting in complete thenar paralysis. A diagnosis of complete failure of median nerve regeneration with an ulnar nerve supply by a distal crossover was made.

The median nerve was explored revealing scar tissue encasing a $4 \mathrm{~cm}$ segment. The repair site was intact. Because the patient had no evidence of nerve regeneration, the scarred nerve was excised and a three cable sural nerve graft was performed.

Four months later the patient's incision healed, range of motion was good and Tinel's sign had advanced $4 \mathrm{~cm}$ into the palm. Two years after grafting, repeat EMG confirmed a Riche-Cannieu connection.

\section{Case 2}

A 20-year-old right hand dominant female security guard presented to the emergency room on January 10, 1989 after slipping during pursuit of a shoplifter. She had cut her left forearm on a broken glass bottle.

On examination, she had a $3 \mathrm{~cm}$ laceration at the radial side of the volar aspect of the left wrist. There was arterial bleeding, controlled by a pressure dressing. Two point discrimination (2PD) was greater than $20 \mathrm{~mm}$ on the volar aspect of the thumb, index and middle fingers, and was $3 \mathrm{~mm}$ on the ulnar border of little finger. She had complete, although painful, flexion of all fingers and weak thenar function. Capillary refill was normal. Surgical exploration revealed that she had the complete transection of palmaris longus tendon, ulnar artery and median nerve, with partial lacerations of all the flexor digitorum superficialis tendons. After repair of these tendons, microsuture of the ulnar artery and median nerve was completed.

Eight months later she had good left thenar bulk and function. However, grip and pinch strength were measurably weaker on the left side (18 kg versus $24 \mathrm{~kg}$ for the first and $3.5 \mathrm{~kg}$ versus $5.5 \mathrm{~kg}$ for the latter). $2 \mathrm{PD}$ was greater than $20 \mathrm{~mm}$ in the left median 
nerve distribution and pinprick produced hyperesthesia. She had a diffuse Tinel's sign distal to the site of repair and into the proximal palm. EMG of the left APB showed fibrillation potentials along with a single motor unit pattern of light intensity on voluntary action. There were also occasional high amplitude, prolonged duration and polyphasic motor unit potentials. There was prolonged motor latency and no sensory potentials in the median nerve. Partial regeneration of the median nerve was postulated and she was scheduled for operative re-exploration.

During the operation, a fusiform mass of fibrous scar tissue was discovered at the region of repair. An internal neurolysis was performed. She continued with physiotherapy and intermittent follow-up. Two-and-a-half years after her injury she had strength and range of motion that was bilaterally comparable and progression of Tinel's sign into the fingers. Repeat EMG was consistent with a Riche-Cannieu connection.

\section{DISCUSSION}

Normal innervation of the intrinsic muscles of the hand is considered to consist of median nerve control of the APB, opponens pollicis, superficial head of the flexor pollicis brevis (FPB) and the radial two lumbricals, and ulnar nerve control of the hypothenars, adductor pollicis, deep head of the FPB, interossei and remaining lumbricals (1-4). Anatomical changes in this pattern have been described and today EMG data show that the previously held constant neural pattern is probably more the exception than the rule.

Neural anomalies in the upper extremity have been frequently described in the literature. The well known Martin-Gruber anastomosis was first described by Martin in 1763 and then Gruber in 1870 and refers to a connection between the median and ulnar nerves in the forearm. The mnemonic device 'median gives' denotes the direction the fibres appear to take. Recent investigators have used EMG in large numbers of subjects to demonstrate that the Martin-Gruber connection occurs in approximately $17 \%$ of the population. It is bilateral in $68 \%$ of these, and is usually found between $3 \mathrm{~cm}$ and $10 \mathrm{~cm}$ distal to the antecubital fossa $(5,6)$. Thus a low median injury can result in median-type sensory loss with intact thenar function, occurring with high stimulation of the median nerve.

Wartime injuries have been used to describe anomalies of innervation, especially in the upper extremity. Rowntree (7) reported on 102 median nerve and 124 ulnar nerve injuries in soldiers and concluded that $20 \%$ appeared to have some type of anomalous innervation ranging from a complete ulnar to complete median hand. He noted that $36 \%$ of FPB muscles appeared to be supplied by the median nerve as expected and $47 \%$ by the ulnar nerve, with $17 \%$ being supplied by both. Cliffton (8) looked at a smaller number of injured soldiers and found seven of 150 to have complete median transections with sensory losses but intact thenar function.

Cannieu (9) dissected 20 cadaver hands and discovered a connection between the recurrent branch of the median nerve and the deep branch of the ulnar nerve in three of these cases. He described a neural loop coming from the ulnar nerve, going between the two heads of the adductor pollicis, and circling round the tendon of the flexor pollicis longus. The following year, Riche (10) described three distinct anatomical patterns of this connection observed in 12 hand dissections. The first was via a branch lying over the 
tendon of the flexor pollicis longus connecting the branch of the ulnar nerve going to the deep head of the FPB and the branch of the median nerve going to the superficial head of the FPB. The second was a connection lying across the first lumbrical, and the third was a branch piercing the adductor pollicis and anastomosing within the muscle substance $(10,11)$. In 1971 Harness and Sekeles (12) looked at 35 hands and found connections between the ulnar and median branches in $77 \%$ of the cases. Bonnel and Vila (13) found this connection in 14 of 50 hands and saw two cases where the ulnar territory included the whole FPB and opponens pollicis. Falconer and Spinner (3) dissected 10 hands and described such a connection in three. This tiny nerve twig has become known as the Riche-Cannieu anastomosis after the earliest authors. The mnemonic 'can you reach opposition' indicates that the ulnar nerve supplies the thenar musculature anomalously in the Riche-Cannieu situation.

Electrophysiologists have developed techniques to determine the relative contributions of the ulnar and median nerves to hand function. Kimura and Ayyar (14) used a collision EMG technique in 150 hands to show that the ulnar nerve contributes to the innervation of the APB in the majority. They showed a statistically significant difference in the incidence of ulnar connection to the APB in American Blacks and Caucasians (14). The average contribution of the APB was calculated to be $27.6 \%$, implying that the median nerve still contributed the bulk of the motor control (14). When Raudino (15) repeated this study in 34 Italian subjects he found the average ulnar contribution to the APB to be $19.8 \%$. Nerve stimulation combined with selective nerve blocks can best demonstrate dual innervation of the APB, opponens pollicis and first dorsal interosseous (16).

The Riche-Cannieu connection is not the only variation from classical peripheral nerve anatomy in the palm observed. Structural anomalies, such as an ulnar nerve loop encircling the hook of the hamate, have been found in $9 \%$ of 77 hands $(17,18)$. Motor anomalies include first dorsal interosseous and abductor digiti minimi innervation by the median nerve (1). Sensory anomalies include links between the ulnar nerve and the third common digital branch (19).

\section{Interpretation of the cases}

In case 1, a proven median nerve transection at the wrist presented with median sensory losses but intact thenar function. This could be explained by a Martin-Gruber anastomosis, a Riche-Cannieu connection or by partial reinnervation. The initial degree of weakness was unknown although it was suspected that it was minimal because the patient continued with his work on the day of injury. Partial reinnervation seemed unlikely because sensory deficit was unchanged and Tinel's sign did not advance. The EMG at 10 months showed polyphasic potentials and some units of increased duration and amplitude suggesting reinnervation of the APB from possible ulnar nerve sprouting (20). Occasional fibrillations indicated that there was still some degree of denervation. It was concluded that this was not a Martin-Gruber situation because stimulation of the median nerve at the elbow did not result in motor activity in the APB. Motor control came from the ulnar nerve below the wrist because blocking it in that location produced paralysis. Thus a Riche-Cannieu connection was postulated in this patient. 
In case 2, the EMG strongly suggested a Riche-Cannieu connection because it showed fibrillation potentials (and thus denervation) together with a uniform motor unit potential of reduced intensity, consistent with partial innervation by the ulnar nerve. Again there was evidence of reinnervtion with polyphasic potentials and this could have been from ulnar sprouting or median regeneration because the patient had a diffuse Tinel's sign along the probable route of the reinnervation.

If the Riche-Cannieu connection is so common (in $90 \%$ of American Caucasians according to Kimura and Ayyar), why is thenar muscle activity still considered reliable as a test of median nerve function? Because the level of stimulation used for EMG testing which revealed this high incidence of the anomaly was supramaximal, it may not reflect the in vivo capabilities. On the other hand, these studies show that the minority of motor control comes from the ulnar nerve (average about $30 \%$ of the total), and this may not be enough to produce movement reliably. It is possible that these ulnar nerve motor endplates are physiologically unused motor connections to the thenar muscles that can become functional in the appropriate circumstances.

\section{CONCLUSION}

Nerve anomalies can distort the clinical picture following traumatic nerve injuries. The Riche-Cannieu connection between the deep branch of the ulnar nerve and the recurrent motor branch of the median nerve in the palm is a highly frequent occurrence whose importance seems to be unappreciated. Careful evaluation of unusual findings in nerve injuries is necessary, using not only clinical examination but also nerve conduction studies and EMG.

ACKNOWLEDGEMENT: We acknowledge the participation of Dr Robert Cartotto in the management of one patient discussed above and thus for this project's inspiration.

\section{REFERENCES}

1. Murphey F, Kirklin JW, Finlayson AI. Anomalous innervation of the intrinsic muscles of the hand. Surg Gynecol Obs 1946;83:15-23.

2. Dykes RW, Terzis JK. Functional anatomy of the deep motor branch of the ulnar nerve. Clin Orthop 1977;128:167-79.

3. Falconer D, Spinner M. Anatomic variations in the motor and sensory supply of the thumb. Clin Orthop 1985;195:83-96.

4. Leibovic SJ, Hastings H. Martin-Gruber revisited. J Hand Surg 1992;17A:47-53.

5. Kimura J, Murphy MJ, Varda DJ. Electrophysiological study of anomalous innervation of intrinsic hand muscles. Arch Neurol 1976;33:842-4.

6. Uchida Y, Sugioka Y. Electrodiagnosis of Martin-Gruber connection and its clinical importance in peripheral nerve surgery. J Hand Surg 1992;17A:54-9.

7. Rowntree T. Anomalous innervation of the hand muscles. J Bone Joint Surg 1949;31B:505-10.

8. Cliffton EE. Unusual innervation of the intrinsic muscles of the hand by median and ulnar nerves. Surgery 1948;23:12-31. 
9. Cannieu JMA. Recherche sur l'innervation de l'eminence thenar par le cubital. J Med Bordeaux 1896:377-9.

10. Riche P. Le nerf cubital et les muscles de l'eminence thenar. Bull Soc Anat Paris 1897;72:251-2.

11. Mannerfeldt L. Studies on the hand in ulnar nerve paralysis. Acta Orthop Scand 1966;87(Suppl):23-142.

12. Harness D, Sekeles E. The double anastomotic innervation of thenar muscles. J Anat 1971;109:461-6.

13. Bonnel F, Vila RM. Anatomical study of the ulnar nerve in the hand. J Hand Surg 1985;10B:165-8.

14. Kimura I, Ayyar DR. The hand neural communication between the ulnar and median nerve: electrophysiological detection. Electromyogr Clin Neurophysiol 1984;24:409-14. 15. Raudino F. Electrophysiologic study of anomalous innervation of the intrinsic hand muscles. Electromyogr Clin Neurophysiol 1989;29:359-61.

16. Dumitru D, Walsh NE, Weber CF. Electrophysiologic study of the Riche-Cannieu anomaly. Electromyogr Clin Neurophysiol 1988;28:27-31.

17. Bergfield TG, Aulicino PL. Variations of the deep motor branch of the ulnar nerve at the wrist. J Hand Surg 1988;13A:368-9.

18. Rogers MR, Bergfield TG, Aulicino PL. A neural loop of the deep motor branch of the ulnar nerve: an anatomic study. J Hand Surg 1991;16A:269-71.

19. Ferrari GP, Gilbert A. The superficial anastomosis in the palm of the hand between the ulnar and median nerve. J Hand Surg 1991;16B:511-4.

20. Brown MC, Ironton R. Sprouting and regression of neuromuscular synapses in partially denervated mammalian muscles. J Physiol 1978;27B:325-48. 